\title{
RISK CLUSTER ASSOCIATED WITH SOCIAL DRINKING IN ADOLESCENCE
}

\section{Galya D. Chamova, Georgi M. Sarov ${ }^{1}$}

Department of Social Medicine and Healthcare Management, Medical Faculty, Trakia University ${ }^{2}$ Department of Pathophysiology, Medical Faculty, Trakia University, Stara Zagora, Bulgaria
Corresponding author:

Galya D. Chamova

Medical Faculty, Trakia University

11, Armeiska Str.

Stara Zagora, 6003

Bulgaria

e-mail: galia.chamova@gmail.com

Received: February 18, 2016

Revision received: March 25, 2016

Accepted: May 30, 2016

\section{Summary}

Recent scientific evidence has shown that risk behaviors tend to form a risk cluster, but less attention is paid to clustering ability of light forms of risky behavior like social drinking. The objective of the study was to analyze the risk clustering potential of social drinking. We conducted a survey using a self-completed questionnaire. Of 903 students (aged 15-19), 279 (30.9\%) were found to be abstainers (NDA), and $455(50.39 \%)$ were social drinkers (SDA). These two groups were compared statistically, concerning smoking and drugs use among them and their significant others. SDAs were more likely to smoke $(\mathrm{OR}=3.29 ; 95 \%$ CI 2.35-4.59) than NDAs but not more likely to use soft drugs. Their fathers $(\mathrm{OR}=1.4$; $95 \%$ CI 1.04-1.89), friends (OR=1.78; 95\% CI 1.31-2.42) and lovers $(\mathrm{OR}=2.01 ; 95 \%$ CI $1.39-2.89)$ were also significantly more likely to smoke, but only friends were more likely to use soft drugs (OR $=1.75$; $95 \%$ CI 1.19 2.58). SDAs were also more likely to start smoking in order to be closer to their peers $(\mathrm{OR}=1.84 ; 95 \%$ CI 1.01 3.37 ) and to smoke when communicate with peers $(\mathrm{OR}=2.12 ; 95 \%$ CI $1.40-3.21)$. Risk clustering in social drinking adolescents is limited to smoking and does not expand to drug use, irrespective of provocation by friends. Heavy smoking among SDAs' significant others might contribute for SDA smoking. So SDAs seem to be resistant to the psycho-social mechanisms adding drug use to drinking but sensitive to psycho-social mechanisms adding smoking to drinking.

Key words: risk cluster, parents, friends, significant others, adolescents, alcohol

\section{Introduction}

Risk clustering is the accumulation of multiple risk behaviors in one person. This phenomenon has become more and more interesting to investigators during the last decade because of increased risk for health and multiplicative effect in health promotion $[1,2]$. According to literature, risk clusters associate with increased general mortality, cancer and cardiovascular disease death rate $[3,4]$, as well as with decreased subjective health in the absence of the disease $[5,6]$. Some authors point out possible benefits for preventive intervention, simultaneously addressing multiple risk factors, as compared to many interventions directed to single risk factors [7- 
9].

The notion ,risk clustering” itself is disputable. It comes from the evidence about association between different risk factors $[1,10$ 12] and the suggestion that one risk behavior could promote the appearance of additional risky behaviors in the same person $[3,13,14]$. Some authors think that risky behaviors are indeed capable of mutual induction $[15,16]$, while others support the opinion that mutual induction is overestimated [17] and needs additional confirmation [8]. McAloney et al. (2013) highlighted that a more precise differentiation is needed between cluster (a set of interrelated and inducible risk behaviors) and co-occurrence (set of risk behaviors, which are not proven to be mutually induced) [18]. Some investigators in the field support that risk clustering may be due to other reasons such as socio-demographic factors $[19,20]$. In this paper we aim to investigate the role of significant others in risk cluster formation in social alcohol drinking of adolescents.

\section{Patients and Methods}

\section{Conception and measurements}

We wanted to test a hypothesis about possible social mechanisms for risk clusters induction. Two main kind of social influences are recognized in the field - social control theory [21] and social learning theory [22]. In order to reveal social learning processes (behavior modeling) we collected data about risky behavior of respondents and their significant others.

Social control processes were studied in two directions: 1) social pressure was studied by means of questions about offers of cigarettes, alcohol and drugs, coming from significant others; 2) social selection mechanisms were indicated by means of questions about conscious reasons of risky behavior initiation (to become closer with peers) and repetitive stimulation of risky behavior in connection with some selecting situations (parties).

\section{Study design}

All students from 9th to 12 th grades (15-19 aged) in three secondary schools in Stara Zagora, Bulgaria were invited to participate in the survey with a cross-sectional design intended to reveal some psychosocial determinants of risk behavior in adolescence. The study protocol was approved by the Ethics Committee for Clinical Research of the Medical Faculty, Trakia University, Stara
Zagora, Bulgaria and the Regional Inspectorate of the Ministry of Education of Bulgaria. To increase the response rate, the survey was conducted in class hours in cooperation with the school authorities. The students were placed in large rooms and seated at sufficient distance from each other to provide independent and anonymous answers to the questions. To provide maximum reliability of the data, the responses were collected in a sealed urn, and each student was free to refuse participation.

\section{Participants}

A total of 1077 students were invited and 1051 of them accepted to participate in the study. Of these, 903 filled out the questionnaire correctly and were included in the survey (response rate: 83.8\%). As we studied drinking models (habits), we did not ask respondents to detail the quantity and type of alcohol consumed by them and their significant others, but to focus on the drinking pattern. In this regard we categorized three drinking patterns: no drinking (abstainers); casual drinking (social drinking - only on special and rare occasions) and regular drinking (no need of special occasions to drink). Respondents were asked to indicate which pattern corresponded to their own drinking behavior. On the base of this categorization, 455 of the respondents $(50.39 \%)$ identified themselves as social drinkers (SDA), 169 - as regular drinkers (RDA) and $279(30.9 \%)$ - as abstainers (NDA). In this study SDAs and NDAs were compared statistically.

\section{Data analysis}

The groups of abstainers (NDA) and social drinkers (SDA) were compared statistically, concerning smoking and drugs use among them and among their significant others. Descriptive statistics, Chi-square test and logistic regression were applied.

\section{Results}

In our previous report on the same sample [23] we found significant positive association between social drinking patterns of respondents and their significant others that could be explained with social modeling and social pressure mechanisms. In this paper we concentrate on cigarette smoking and drug use of SDA.

We found that SDAs were more likely to smoke than NDAs (Table 1), which is true for all smoking patterns (social, moderate and heavy 
smoking). SDAs were also less likely to be intolerant to cigarette smoke. There were no significant differences between SDAs and NDAs in drug use, while in a previous analysis of the same sample [24] we found that regularly drinking adolescents (RDA) were more likely to use marijuana than NDAs.

Table 1. Additional risk behaviors in association with social drinking in adolescents

\begin{tabular}{|c|c|c|c|c|c|}
\hline & \multirow{2}{*}{$\begin{array}{l}\text { SDA }(n=455) \\
\%(\mathrm{SE})\end{array}$} & \multicolumn{2}{|l|}{ NDA $(n=279)$} & \multirow[b]{2}{*}{ OR } & \multirow[b]{2}{*}{$95 \% \mathrm{CI}$} \\
\hline & & $\%(\mathrm{SE})$ & $\mathrm{p}<$ & & \\
\hline Smoking & $49.45 \pm 2.34$ & $22.94 \pm 2.52$ & 0.01 & 3.29 & $2.35-4.59$ \\
\hline - $\quad$ Social smoking & $17.58 \pm 1.78$ & $7.17 \pm 1.54$ & 0.001 & 2.76 & $1.65-4.62$ \\
\hline - Moderate smoking (up to 10 cigarettes per day) & $17.14 \pm 1.77$ & $11.11 \pm 1.88$ & 0.05 & 1.66 & $1.06-2.59$ \\
\hline - Heavy smoking (more than 10 cigarettes per day) & $14.73 \pm 1.66$ & $4.66 \pm 1.26$ & 0.001 & 3.53 & $1.91-6.53$ \\
\hline Cigarette smoke is very unpleasant for me & $30.55 \pm 2.16$ & $39.78 \pm 2.93$ & 0.05 & 0.67 & $0.49-0.91$ \\
\hline Previous drug use & $8.35 \pm 1.30$ & $4.66 \pm 1.26$ & NS & 1.86 & $0.98-3.57$ \\
\hline Current marijuana use & $6.15 \pm 1.13$ & $3.94 \pm 1.17$ & NS & 1.60 & $0.78-3.26$ \\
\hline
\end{tabular}

Concerning risky behavior models, we found that all the significant others of SDAs (except mothers) were more likely to smoke and all the significant others were more likely to be heavy smokers (Table 2) with no significant difference in other smoking patterns. SDAs were also more likely to have friends that currently used marijuana.

Table 2. Significant differences in smoking and drug use among significant others of SDAs and NDAs

\begin{tabular}{lcllll}
\hline & $\begin{array}{l}\text { SDA }(\mathrm{n}=455) \\
\%(\mathrm{SE})\end{array}$ & $\begin{array}{l}\mathrm{NDA}(\mathrm{n}=279) \\
\%(\mathrm{SE})\end{array}$ & $\mathrm{p}<$ & OR & $95 \% \mathrm{CI}$ \\
\hline Smoking & & & & & \\
father & $54.29 \pm 2.34$ & $45.88 \pm 2.98$ & 0.05 & 1.40 & $1.04-1.89$ \\
mother & $55.60 \pm 2.33$ & $48.75 \pm 2.99$ & $\mathrm{NS}$ & 1.32 & $0.98-1.78$ \\
friends & $68.35 \pm 2.18$ & $54.84 \pm 2.98$ & 0.001 & 1.78 & $1.31-2.42$ \\
lover & $36.89 \pm 2.38$ & $22.55 \pm 2.73$ & 0.001 & 2.01 & $1.39-2.89$ \\
\hline Heavy smoking (more than 10 cigarettes per day) & & & & \\
father & $29.67 \pm 2.14$ & $22.22 \pm 2.49$ & 0.05 & 1.48 & $1.04-2.09$ \\
mother & $23.52 \pm 1.99$ & $15.77 \pm 2.18$ & 0.05 & 1.64 & $1.11-2.42$ \\
friends & $27.91 \pm 2.10$ & $17.92 \pm 2.30$ & 0.01 & 1.77 & $1.23-2.56$ \\
lover & $15.05 \pm 1.76$ & $6.81 \pm 1.64$ & 0.01 & 2.42 & $1.36-4.31$ \\
\hline Current marijuana use & & & & & \\
friends & $24.18 \pm 2.01$ & $15.41 \pm 2.16$ & 0.01 & 1.75 & $1.19-2.58$ \\
lover & $4.85 \pm 1.06$ & $2.98 \pm 1.11$ & $\mathrm{NS}$ & 1.66 & $0.69-3.99$ \\
\hline
\end{tabular}

With regard to social pressure, it was found that no significant differences existed between cigarette and drugs offers coming from significant others (Table 3) with only one exception: SDAs were more likely to receive drug offers from their friends. 
Table 3. Significant differences in cigarette and drugs offers coming from significant others of SDAs and NDAs

\begin{tabular}{|c|c|c|c|c|c|}
\hline & $\begin{array}{l}\text { SDA }(n=455) \\
\%(\mathrm{SE})\end{array}$ & $\begin{array}{l}\text { NDA }(n=279) \\
\%(\mathrm{SE})\end{array}$ & $\mathrm{p}<$ & OR & $95 \% \mathrm{CI}$ \\
\hline \multicolumn{6}{|c|}{ Cigarette offers coming from } \\
\hline father & $3.96 \pm 0.91$ & $1.79 \pm 0.79$ & NS & 2.26 & $0.83-6.15$ \\
\hline mother & $4.40 \pm 0.96$ & $2.15 \pm 0.87$ & NS & 2.09 & $0.83-5.27$ \\
\hline friends & $37.58 \pm 2.27$ & $33.33 \pm 2.82$ & NS & 1.20 & $0.88-1.65$ \\
\hline lover & $7.52 \pm 1.30$ & $6.81 \pm 1.64$ & NS & 1.11 & $0.60-2.08$ \\
\hline \multicolumn{6}{|c|}{ Drugs offers coming from } \\
\hline friends & $17.36 \pm 1.78$ & $10.75 \pm 1.85$ & 0.05 & 1.74 & $1.11-2.73$ \\
\hline
\end{tabular}

The indicators of personal risky choice showed that SDAs were more likely to initiate alcohol consumption and smoking in order to become closer to peers, but not more likely to initiate drug use and sexual practices because of the same reason (Table 4). A party was more likely to be the place of alcohol and sexual initiation of SDAs, as well as for alcohol misuse initiation, but not for smoking and drug use initiation. In company with friends, SDAs were more likely to increase their smoking and alcohol use but not more likely to increase drug use and not more likely to feel sexually aroused.

Table 4. Significant differences in conscious motivation for risky behavior initiation between SDAs and NDAs

\begin{tabular}{lccccc}
\hline & $\begin{array}{l}\text { SDA }(\mathrm{n}=455) \\
\%(\mathrm{SE})\end{array}$ & $\begin{array}{l}\text { NDA }(\mathrm{n}=279) \\
\%(\mathrm{SE})\end{array}$ & $\mathrm{p}<$ & OR & $95 \% \mathrm{CI}$ \\
\hline To be closer to peers, I ...: & & & & & \\
I started smoking & $9.45 \pm 1.37$ & $5.38 \pm 1.35$ & 0.05 & 1.84 & $1.01-3.37$ \\
I started alcohol use & $8.35 \pm 1.30$ & $2.87 \pm 1.00$ & 0.01 & 3.09 & $1.42-6.72$ \\
I started drug use & $3.30 \pm 0.84$ & $2.87 \pm 1.00$ & $\mathrm{NS}$ & 1.15 & $0.48-2.76$ \\
I started making sex & $7.03 \pm 1.20$ & $5.73 \pm 1.39$ & $\mathrm{NS}$ & 1.24 & $0.67-2.31$ \\
At party for the first time: & & & & & \\
I smoked & $11.21 \pm 1.48$ & $7.53 \pm 1.58$ & $\mathrm{NS}$ & 1.55 & $0.91-2.64$ \\
I drank alcohol & $29.45 \pm 2.14$ & $19.00 \pm 2.35$ & 0.01 & 1.78 & $1.24-2.55$ \\
I felt drunk & $34.29 \pm 2.23$ & $17.92 \pm 2.30$ & 0.001 & 2.39 & $1.66-3.43$ \\
I tried drugs & $2.64 \pm 0.75$ & $1.43 \pm 0.71$ & $\mathrm{NS}$ & 1.86 & $0.59-5.83$ \\
I had sex & $11.21 \pm 1.48$ & $6.45 \pm 1.47$ & 0.05 & 1.83 & $1.05-3.20$ \\
Compared to being alone, in company & with friends, I ... more: & & & \\
drink & $32.31 \pm 2.19$ & $14.34 \pm 2.10$ & 0.001 & 2.85 & $1.93-4.20$ \\
smoke & $23.30 \pm 1.98$ & $12.54 \pm 1.98$ & 0.001 & 2.12 & $1.40-3.21$ \\
use drugs & $1.98 \pm 0.65$ & $1.43 \pm 0.71$ & NS & 1.39 & $0.42-4.55$ \\
think about sex & $19.78 \pm 1.87$ & $17.56 \pm 2.28$ & NS & 1.16 & $0.79-1.70$ \\
\hline
\end{tabular}

\section{Discussion}

As pointed in the literature $[1,3,10-14]$, our study confirms that the association between various risk factors indeed happens in SDAs, as it was found as present in RDAs [24]. In both cases, we found an association between drinking, smoking, and premature sex, but only in RDAs this association included drug use. So we have arguments to conclude that with increased 
frequency of alcohol use, risk clustering increased and this conclusion supports the suggestion that one reason for clustering could be a mutual induction of risky behaviors $[15,16]$.

In contrast with such a conclusion, we found that social influences coming from others could be the reason for risky behavior multiplication because their risky behavior patterns corresponded to risky behavior patterns in respondents, as pointed by other investigators $[25,26]$. In this respect, we are closer to the suggestion, that socio-demographic factors [19, 20 ] could be responsible for risk clustering.

Our data confirmed that social influences of smoking could be explained in terms of social modeling, since no significant differences were found in cigarette offers made by significant others. It seemed that social pressure and social modeling were not likely to be effective for drug use and SDAs remained resistant to both drug use models and drug offers from friends.

The instrumental and symbolic meaning of risky behavior for social integration is well recognised by SDAs and they conform to react. But SDAs' conformism is limited to smoking and drinking and does not spread to drug use as it happens with RDAs [24].

\section{Conclusions}

This study gives reasons to suggest that risk clustering in adolescence may due to both social influences and personal decisions. Both social modeling and social control mechanisms stimulate risky clustering but, in contrast with RDAs, SDAs limit these influences consciously and resist to socially intolerable forms of behavior. The social compliance is much less profound in SDAs than in RDAs. SDAs comply with adolescent risky values but do not allow to be assimilated by them, as do RDAs [24]. This suggests that SDAs' cognition is more socially independent than that of RDAs', and this relative personal independence plays a certain protective role. So we come to the conclusion that personal independence may be the protective factor that could counteract social risky influences and prevent risky behavior multiplication. Maybe personal independence should be used in preventive intervention to reduce risk clustering effect of juvenile culture.

\section{Acknowledgements}

This study was supported by an institutional research grant at Medical Faculty, Trakia University, Stara Zagora, Bulgaria (grant number 26/2014).

\section{References}

1. Pronk NP, Anderson LH, Crain AL, Martinson BC, O'Connor PJ, Sherwood NE, et al. Meeting recommendations for multiple healthy lifestyle factors: prevalence, clustering, and predictors among adolescent, adult, and senior health plan members. Am J Prev Med. 2004;27:25-33.

2. Pronk NP, Peek CJ, Goldstein MG. Addressing multiple behavioral risk factors in primary care: a synthesis of current knowledge and stakeholder dialogue sessions. Am J Prev Med. 2004;27:4-17.

3. Meng L, Maskarinec G, Lee J, Kolonel LN. Lifestyle factors and chronic diseases: application of a composite risk index. Prev Med. 1999;29:296304.

4. Yusuf HR, Giles WH, Croft JB, Anda RF, Casper ML. Impact of multiple risk factor profiles on determining cardiovascular disease risk. Prev Med. 1998;27:1-9.

5. Johansson S, Sundquist J. Change in lifestyle factors and their influence on health status and allcause mortality. Int J Epidemiol. 1999;28:1073-80.

6. Manderbacka K, Lundberg O, Martikainnen P. Do risk factors behaviours contribute to self-ratings of health? Soc Sci Med. 1999;48:1713-20.

7. Burke V, Milligan RAK, Beilin LJ, Dunbar D, Spencer M, Balde E, et al. Clustering of healthrelated behaviors among 18-year-old Australians. Prev Med. 1997;26:724-33.

8. van Nieuwenhuijzen $M$, Junger $M$, Velderman MK, Wiefferink KH, Paulussen TWGM, Hox J, et al. Clustering of health-compromising behavior and delinquency in adolescents and adults in the Dutch population. Prev Med. 2009;48:572-8.

9. Werch C, Moore M, DiClemente C, Bledsoe R, Jobli E. A multihealth behavior intervention integrating physical activity and substance use prevention for adolescents. Prev Sci. 2005; 6:21326.

10. Sarov GM, Stoyanova M, Georgieva M, Nikolova P, Atanasov P. Some psychological aspects of risk behaviour in young females. In: Proceedings of the 9th National Conference "Modern Tendencies in the Development of Fundamental and Applied Sciences"; 1998 Jun 5-6; Stara Zagora, Bulgaria; 1998. p. 108-11.

11. Sarov GM, Kovachev G, Taneva N, Moskova S, Georgieva M. Some specific social values and behaviour of drinking teenage males. In: 
Proceedings of the 9th National Conference "Modern Tendencies in the Development of Fundamental and Applied Sciences"; 1998 Jun 56; Stara Zagora, Bulgaria; 1998. p. 103-7.

12. Wiefferink CH, Peters L, Hoekstra F, Ten Dam G, Buijs GJ, Paulussen TGW. Clustering of healthrelated behaviors and their determinants: possible consequences for school health interventions. Prev Sci. 2006;7(2):127-49.

13. Huang DYC, Lanza HI, Murphy DA, Hser YI. Parallel development of risk behaviors in adolescence: potential pathways to co-occurrence. Int J Behav Dev. 2012;36(4):247-57.

14. Otten R, Engels RC, van de Ven MO, Bricker JB. Parental and adolescents smoking stages: the role of parents' current and former smoking, and family structure. J Behav Med. 2007;30(2):143-54.

15. Diez E, Barniol J, Nebot M, Juarez O, Martin M, Villalbi JR. Health-related behaviors in secondary-school students: sexual relations and tobacco, alcohol and cannabis consumption. Gac Sanit. 1998; 12(6):272-80.

16. Takakura M, Ueji M, Sakihara S. Covariation of cigarette smoking and other health-risk behaviors among Japanese high school students: a preliminary study. J Epidemiol. 2001;11(5):224-8.

17. Guilamo-Ramos V, Litardo HA, Jaccard J. Prevention programs for reducing adolescent problem behaviors: Implications of the cooccurrence of problem behaviors in adolescence. $\mathrm{J}$ Adolesc Health. 2005;36(1):82-6.

18. McAloney K, Graham H, Law C, Platt L. A scoping review of statistical approaches to the analysis of multiple health-related behaviours.
Prev Med. 2013;56(6):365-71.

19. Laaksonen M, Prättälä R, Lahelma E. Sociodemographic determinants of multiple unhealthy behaviours. Scand J Public Health. 2003;31:37-43.

20. Liang W, Shediac-Rizkallah C, Celentano DD, Rohde C. A population-based study of age and gender differences in patterns of health-related behaviors. Am J Prev Med. 1999;17:8-17.

21. Chassin L, Hussong A, Barrera M Jr, Molina BSG, Trim R, Ritter J. Adolescent substance use. In: Lerner RM, Steinberg L, editors. Handbook of adolescent psychology. 2nd ed. Hoboken (NJ): John Wiley \& Sons, Inc.; 2004. p. 665-96.

22. Bandura A. Social foundations of thought and action: A social cognitive theory. Englewood Cliffs (NJ): Prentice-Hall; 1986.

23. Chamova GD, Sarov GM. Significant others and social alcohol use in adolescents. J Biomed Clin Res. 2015;8(2):145-9.

24. Chamova $\mathrm{G}$. [The role of significant others for risk clustering in regularly alcohol drinking adolescents]. Soc Med (Sofia). 2014;2:22-4. Bulgarian.

25. Pettersson C, Lindén-Boström M, Eriksson C. Parental attitudes and behavior concerning youth alcohol consumption: do sociodemographic factors matter? Scand J Public Health. 2009;37:509-17.

26. Latendresse SJ, Rose RJ, Viken RJ, Pulkkinen L, Kaprio J, Dick DM. Parenting mechanisms in links between parents' and adolescents' alcohol use behaviors. Alcohol Clin Exp Res. 2008;32(2):32230 . 